\title{
JAPANESE BACKPACKING: THE EMERGENCE OF A NEW MARKET SECTOR-A QUEENSLAND CASE STUDY
}

\author{
BRUCE PRIDEAUX* and HIDEKI SHIGA $\dagger$
}

*School of Business Studies, James Cook University, Australia

$\dagger$ Hideki Shiga, School of Tourism and Leisure Management, University of Queensland, Australia

\begin{abstract}
This article reports on a study of Japanese backpackers conducted in Queensland, arguing that this backpacker sector has a range of characteristics that differ from Western backpackers who, to date, have constituted the main representatives of this segment visiting Australia. The research identified a number of areas where the characteristics of Japanese backpackers varied from those of the overall backpacker population in Australia. One major point of difference was the emphasis placed by this market segment on learning English and a preference for activities that focused on the environment rather than other activities such as soft adventure.
\end{abstract}

Key words: Backpackers; Japanese; Queensland; Cross-cultural studies; Australia

\section{Introduction}

Backpacking is an approach to travel that emerged from even earlier forms of low-cost travel such as tramping (Richards \& Wilson, 2004) and is characterized by low accommodation budgets, a desire to meet fellow travelers and hosts in informal situations, and, for some, a willingness to go beyond the usual tourism focal points and explore new areas. In another sense backpacking is an approach to travel that has an important social element grafted onto the more traditional travel activities of going, seeing, and doing. From a different perspective, Ateljevic and Doorne (2004) describe the backpacker phenomenon as "a metaphor of mobility (that) has in the contemporary context become representative of a travel lifestyle and an expression of identify, as well as a coherent industrial complex in its own right" (p. 60). In the early period of contemporary backpacking there was relatively little structure to the sector; however, in the last two decades a sophisticated and specialized backpacker industry has emerged. Some of the informality as well as uncertainty of early backpacking has gone, and in terms of Cohen's (1972) typology of traveler types, the drifter and explorer backpackers of the 1960s and early 1970s have been largely replaced by mass backpacking in the 1990s. As the trend towards a formal structure for backpacking has emerged, organized tourism experiences have been developed, packaged, 
and marketed as a form of mass tourism to create the contemporary backpacking experience. One component of this trend has been fostered by concepts such as work abroad schemes and the gap year, where students leaving secondary school travel and work for a year prior to undertaking tertiary studies or embarking on careers. As many backpacking markets have moved towards mass tourism, backpacking has emerged as an "acceptable" form of travel for many young people and a growing number of older tourists.

The growing popularity of backpacking has been recognized by many destinations and in Australia this travel sector accounted for $10 \%$ of all arrivals in 2003 (Australian Tourist Commission, 2004). In contrast to the rapid increase in backpacking as a distinct market segment, intensive investigation of this phenomenon in the academic literature has only occurred in the last few years, despite the early work by Cohen (1972, 1973, 1974), Pearce (1990), Haigh (1995), and Loker (1992) that to a large extent established the definitions of this form of travel. The recent publication of papers (Richards \& Wilson, 2004) presented at the first international forum on backpacking held in 2002, and the establishment of the Backpacking Research Group (BRG) by the Association for Tourism and Leisure Education (ATLAS) were important steps in placing research into the backpacking phenomenon onto the agenda of the research community. In an excellent review of the backpacker literature, Ateljevic and Doorne (2004) traced the development of research and the evolution of conceptualizations of backpacking, commencing with the early investigations of Cohen (1972, 1973, 1974). Overall however, the literature has not kept pace with the growth of backpacking, has focused on backpackers originating from Western countries, and has largely ignored the growth of backpacking in other societies.

Backpackers from non-Western countries can be expected to exhibit motivations and expectations that differ from their Western counterparts. Ateljevic and Doorne's (2004) observation that backpacking represents a "travel lifestyle and an expression of identify" (p. 60) has yet to be analyzed in a non-Western context, and given the significant differences between Western and non-Western expressions of culture and the rights and responsibilities of membership of social groups, this group of travelers may produce new forms of backpacking or demand for backpacking experiences. As will be demonstrated later in this article, there are significant differences between Japanese backpackers and their Western counterparts. The implications of these differences have yet to be understood in the context of the backpacking phenomenon and the industry that has emerged to service backpacking. It may be that the outward symbols of backpacking such as independent travel, guide books, Internet cafes, and a subculture based on hedonistic activities may not provide the forms of travel experience sought by non-Western backpackers.

One area of backpacking that has received little attention is the Japanese backpacking market. While relatively small in comparison to total Japanese outbound travel and overall backpacker flows originating in Europe, North America, Australia, and New Zealand, this group of travelers can be viewed as the first of a new wave of backpackers from Asia and in smaller numbers from Latin America in the next decade. Japanese tourists are often stereotyped as preferring group tours and having relatively little interaction with host communities. In recent years the pattern of outbound travel from Japan, particularly for young people, has begun to change and there is a new trend emerging based on independent travel (Anderson, Prentice, \& Watanabe, 2000). Chronologically, Japanese backpacking is a much later phenomenon than Western backpacking. Western backpacking, particularly European, emerged from the social upheavals associated with the youth culture of antiestablishment protest in the 1960s (Cohen, 2004). Backpackers of this era can be described as the first postmodern tourists, seeking hedonistic experiences characterized by free love, a counterculture based on drugs and antiestablishment rhetoric, and a desire to experiment during travel experiences.

Non-Western backpacking has its origins in quite different circumstances, usually predicated on sustained periods of economic growth, changing societal views on the worth of travel to all members of society, and importantly an easing of restrictions on overseas travel. A parallel to the analysis of differences between Western and Non-Western backpacking indicates the importance of cross-cultural studies in this area of research. Whereas members of Western society have been described as having norms centered on individualism and nationalism, non- 
Western societies exhibit a different set of norms that may include collectivism, a respect for authority, and interpersonal harmony (Kim \& Lee, 2000). Thus, for the youth of nations that value collectivism and respect for authority, extended independent travel has an entirely different social context compared to societies where individualism is valued and encouraged. Contemporary Western backpacking has developed a reputation, although not always deserved, of having few social restraints and where the mores of the parent society are seen as irreverent to the pleasure-seeking pursuits of participants. This may not be the path that will be followed by non-Western travelers, and consequently this study was undertaken as the first step towards developing a profile of Japanese backpackers.

The definition of backpacking used in this article is based on that proposed by Pearce (1990, p. 1), who described backpackers as tourists who have a preference for budget accommodation and who have some but not necessarily all of the following criteria:

- An emphasis on meeting other travelers;

- An independently organized and flexible travel schedule;

- Takes longer rather than very brief holidays; and

- An emphasis on informal and participatory holiday activities.

Pearce argued that backpacking is best defined socially, rather than economically or demographically, because backpacking is an approach to travel that is not defined by the amount of money spent or the age of the participant. According to Pearce, evidence of the first of the five criteria outlined, that is a preference for budget accommodation, is essential in defining a backpacker, and the others are normally present to a greater or lesser extent.

\section{Backpacking in Australia}

The backpacker market is an important market for Australia's tourism industry and in the year ending June 2003 backpackers accounted for $10 \%$ $(445,494)$ of the total number of international visitors to Australia and $24 \%$ of the international bed nights (Tourism Queensland, 2003a). Between the years ending June 2000 and 2003 total backpacker nights increased by an average of $0.1 \%$ per annum while total numbers increased by $2.4 \%$ despite global evens such as the Bali bombings, Severe Acute Respiratory Disease (SARS), and the War on Terror. The backpacker market is dominated by the UK with $29 \%$ of arrivals, followed by Europe (excluding the UK and Germany) with $27 \%$ of arrivals, and the US supplying $10 \%$ of arrivals. Japanese backpackers are a relatively small group (17,675 in the year ending June 2003) who stay an average of 60.8 nights. In 2003 the average length of stay for all backpackers was 61.2 nights while average spending per backpacker was $\$ 4,805$ (excluding prepaid inclusive package tours and prepaid international airfares), adding AUD $\$ 2.14$ billion to the nation's export performance. The long-haul nature of Australia as a destination is one reason why many backpackers are likely to stay for extended periods.

Tourism Australia (formerly the Australian Tourist Commission) (2003) research has found that backpackers have "must see" destinations including Sydney, Cairns and the Great Barrier Reef, Byron Bay, Uluru (Ayres Rock), and Fraser Island. Most backpacker travel is focused on coastal destinations between Melbourne in the south and Cairns in the north. A relatively small number of backpackers venture beyond the core destinations into the periphery areas such as Cape York and rural Australia, or to the iconic Uluru region of the Northern Territory. In terms of Cohen's (1972) typology, the majority of backpackers can be considered as being members of a mass tourism backpacker sector. A relatively small number of "explorers" visit the nation's more remote and underdeveloped areas. Even in the backpacker market there is an emphasis on mass, though specifically tailored, tourism experiences such as working holidays (Cooper, O’Mahony, \& Erfurt, 2004).

Tourism Queensland (2003a) identified the top 10 activities participated in by backpackers as:

- Go shopping for pleasure (89\%)

- Go to the beach (including swimming, diving, and surfing) (87\%)

- Pubs/clubs/discos (77\%)

- Visit national parks (70\%)

- Go to markets (67\%)

- Visit botanical gardens or other public gardens (67\%) 
- Visit wildlife parks/zoos/aquariums (66\%)

- Visit museums or art galleries (58\%)

- Bushwalking/rainforest walks (56\%)

- Go on guided tours or excursions $(56 \%)$

Tourism Queensland (2003a) found that 92\% of backpacker respondents ranked word-of-mouth referrals as their most important source of information, followed by friends and relatives $(71 \%)$, guidebooks $(70 \%)$, and the Internet $(62 \%)$.

\section{Japanese Backpacking}

While the number of Japanese backpackers is relatively small, the number of Japanese young people engaging in this form of nontraditional travel is increasing. This trend must be viewed against the connotation of the term "backpacker" in Japan until recently. In the past backpacking was seen as a form of travel that was full of adventure but also "dirty" and dangerous. Aside from Australia, backpacking Japanese are now beginning to make their presence known in many destinations, and a specialized backpacker sector is beginning to emerge to support this new market. Often, backpacking occurs after a young person has spent some time abroad as a student and the overseas experience is concluded with travel as a backpacker. In a number of countries specialist backpacker establishments have emerged to service this market. In Cuba, for example, guidebooks published in Japanese inform readers of several backpacker hostels that have Japanese-speaking staff. In South America, which has a number of countries with significant Japanese immigrant communities, a defined backpacker trail has emerged that specializes in Japanese, including hostels with Japanesespeaking staff.

Backpacking is a relatively new phenomenon in Japan and, while attracting a growing number of young Japanese tourists, has yet to be researched in depth, either in Japan or elsewhere. Compared to the traditional mass market based on inclusive package tours, the backpackers market has a number of unique characteristics such as information search patterns, length of stay, itinerary, and activities participated in. However, as with the more traditional mass Japanese market, language difficulties continue to pose a problem for Japanese backpackers, and methods of dealing with this reality will assist desti- nations provide a better service to the Japanese market sector.

Commenting on recent changes in Japanese travel patterns, Kajiwara (1997) noted that many young Japanese appear to be going abroad for the sheer pleasure of traveling. However, in making this observation Kajiwara adds that in a society where hard work is highly valued the feeling of guilt in seeking pleasure dies hard, and education or other "meaningful aspects" of travel continue to play an intrinsic role in travel. From a different perspective, Kajiwara observed that the influence of the Japanese government's policy of "internationalization" introduced in the 1980s, combined with a growing feeling of a lack of "authenticity" and "value" in everything Japanese, has lead to a deep feeling of malaise that encourages Japanese to travel abroad. Backpacking may be construed to be one way in which Japanese youth have responded to these deep forces within Japanese society.

The recent growth in backpacking reflects a further maturation of the Japanese outbound market. Following the liberalization of Japanese outbound travel in the $1960 \mathrm{~s}$, particularly post-1964, most Japanese tourists traveled on package tours. Recently, there has been a change in this pattern as increasing numbers of Japanese have experienced overseas travel. Examples of this can be seen in the new types of products offered by Japanese travel agencies, including "free style tours" where tourists choose places and duration on a personally tailored plan without a guide. Another new travel product to emerge in the Japanese market has been termed the "Skeleton Tour," or furii-puran (free-plan) package tours, and consists of the airfare and a few nights' accommodation. Frequently the package is offered at lower prices than just the airfare alone. As a result of this pricing structure the bundled accommodation may not always be used. These tours have grown in popularity, but because they are still classified as a group tour for statistical purposes they have distorted the true nature of Japanese Free Independent Travel and Group Inclusive Travel in Australia. If the skeleton tour segment was removed from the "Package Tours" classification in inbound statistics, independent travelers would constitute a larger segment of Japanese inbound tourists.

Study tours are also gaining popularity and include private language schools in Australia, which provide 
courses ranging from 2 weeks' to 12 months' duration. Another tour type is the long stay tour. Demand for this form of travel is increasing. Japanese undertaking this form of travel usually stay in a foreign country for several months (Australian Tourist Commission, 2004). Working holidays are also becoming popular with younger Japanese, echoing trends of youth engaged in working holidays in Europe and North America. Australian Working Holiday Visas allow 18-30-year-old people to stay in Australia for up to 2 years, where the visa holder can attend a language school for 3 months and work for 3 months for one employer. Even where the tourist's language skill is limited many Japanese undertake this form of travel, often finding work in the firms that specialize in servicing the Japanese inbound market such as restaurants, shops, and tour guides (Cooper, 2002). Until very recently it was common for Japanese to work for one company until retirement, but this pattern of employment has begun to change in recent years. Many businesses choose to use contractors for a range of tasks that were once preformed by salaried employees. As a consequence, it has become easier and, importantly, more socially acceptable for employees to quit their job and travel. This was reinforced by the promotion of independent travel by the Japanese government from 1991 in programs such as the "Twoway 21 Tourism Program" (Anderson et al., 2000). An emerging trend is for university students on graduation and for others who have recently left school to travel overseas to learn English.

In 2002 (Tourism Queensland, 2003b) backpackers comprised $3 \%$ of all Japanese visitors to Australia and accounted for $21 \%$ of total Japanese visitor nights. The most popular destination in Australia was New South Wales, which was visited by $62 \%$ of all Japanese backpackers, followed by Queensland (56\%) and Victoria (40\%). Between 1999 and 2002 the number of Japanese backpackers declined, falling $33.2 \%$ from a high of 23,200 in 1999 to 15,540 in 2002. This trend does not mirror the national trend for all Japanese visitors, which while recording a fall in 2001, was 1\% higher in 2002 than in 1999. There is no apparent reason for this fall in backpacker numbers. In keeping with the national trend, the number of Japanese backpackers in Queensland declined in the period 1999 to 2002.

In 2002, Tourism Queensland (2003b) found that Japanese backpackers spent an average of $\$ 4,622$ in
Australia, comprising $\$ 1,850$ on food, drink, and accommodation, $\$ 452$ on shopping, and $\$ 410$ on organized tours. The level of spending was slightly below the average for all backpackers visiting Australia. According to Tourism Queensland (2003a), activities participated in by Japanese backpackers included shopping (82\%), visiting national parks (64\%), going to markets (60\%), and visiting clubs/ pubs and discos $(57 \%)$. The most popular places visited were the Great Barrier Reef and Islands (30\%), national parks (24\%), Southbank park land in Brisbane (23.3\%), Gold Coast theme parks (19\%), markets (14\%), whale watching (13\%), Whitsunday Islands (13\%), Gold Coast hinterland (12\%), and the Daintree region (11\%). The Australian Tourist Commission has not identified Japanese backpackers as a priority market, seeing more potential in the Office Lady, Jukunen (Matures and Silvers), Young Office Ladies, and School Excursion/English studies groups.

\section{Aims and Methodology}

Given the lack of published research on the Japanese backpacker market in Australia this research has three major aims:

- What information sources do Japanese backpackers use?

- What factors motivate Japanese tourists to travel to Australia as backpackers?

- What activities do Japanese backpackers participate in when they visit Australia?

By identifying information sources used, motivations, and main activities participated in, researchers and tourism industry members will be able to develop a better understanding of Japanese backpackers. Queensland was selected as the site for this research because of the popularity of the state with Japanese backpackers. Given the limited nature of previous research, this study was conducted as a scoping exercise to identify the main characteristics of the Japanese backpacker market. The results of this study will identify issues that require more targeted research in the future.

Data were collected using a quantitative questionnaire completed by 120 Japanese backpackers visiting the coastal resort centers of Cairns, Noosa, 
the Sunshine Coast, and the Gold Coast in Queensland. The survey was conducted in Japanese by a Japanese researcher using the convenience sampling method. The survey instrument was piloted prior to conducting the survey and several adjustments made. The questionnaire was conducted in September and potential participants were approached by a research team member and asked in Japanese if they were willing to participate in the survey. The survey was undertaken in areas near where backpackers were staying and is consistent with the distribution methods used by other researchers (Kininmont, 2000; Loker, 1992; Reid, Slaughter, \& Prideaux, 2002). To determine if subjects classified themselves as a backpacker and fitted the definition of backpackers adopted for this research a filter question was asked. Questionnaires were self-administered, although the researcher remained nearby to assist respondents who requested clarification. This approach enabled the researcher to ensure a $100 \%$ response rate. Conducting the survey in person contributed to the successful data collection (Seddighe $\&$ Theocharous, 2002), including the high response rate by participants.

The questionnaire asked respondents a number of sociodemographic questions followed by a series of questions using a 5-point Likert scale. The questions used in the survey instrument were developed after extensive consultation with backpacker accommodation managers who serviced the Japanese market as well as informal conversations with Japanese backpackers. Further questions were based on the results of a review of the backpacker literature.

\section{Limitations}

Two major limitations of this research should be noted. These included a relatively small sample size, a consequence of the small size of the Japanese backpacker market, and the limited time frame of the study. If conducted over a longer time frame this research would provide more in-depth data on travel patterns and would allow more scope for generalizing the findings. As the survey was conducted over a period of 4 weeks it is not representative of the yearly patterns and fluctuations that may occur over the course of a 12-month period.
Results

The gender balance was equally divided between males and females. Most of the male respondents $(75 \%)$ were traveling by themselves while females are more likely to travel in a group of two or more (49\%). Overall, $69 \%$ of respondents were traveling as individuals. This result is significant because of the collective nature of traditional Japanese society, where the influence of the group on the individual can be quite strong. No respondents participated in tours organized by Japanese travel agencies, although in conversations with the researcher many respondents indicated that they were interested in participating in tours arranged by local tour operators. Eighty percent of respondents indicated that they were traveling on independent arrangements while the remainder left some travel arrangements to travel agents.

Most respondents (72\%) possessed a 12-month Working Holiday Visa and expressed an intention to participate in work as well as travel. Males were more likely to be traveling on a Working Visa than females ( $88 \%$ of males and $55 \%$ females). The type of visa issued to Japanese backpackers is important as it has an influence over the type of holiday experience participated in. There are considerable differences in the length of time able to be spent in Australia as well as the activities that may be participated in. Working Holiday Visas are valid for up to 2 years, whereas tourist visas only allows tourists to stay for 3 months and do not permit the holder to engage in employment. Student Visas are valid for the term of the educational course undertaken. The high rate of Working Holiday Visa indicates that most Japanese backpackers are interested in travel experiences as well as working experiences.

Other major sociodemographic data are:

- Eighty percent of respondents were traveling on independent arrangements, the remaining respondents had booked part of the land content through travel agents.

- Fifty-three percent of respondents had traveled to Australia previously.

- Seventy percent of respondents had traveled abroad prior to traveling to Australia.

- Fifty-six percent of respondents expected to stay in Australia for between 6 and 12 months. 
- Nineteen percent of respondents had visited Australia for education, 25\% for a holiday and $45 \%$ for working as well as on holiday.

- Twenty percent of respondents were students.

\section{Information Sources}

In a recent study into information sources used by backpackers in the Whitsunday region, Reid et al. (2003) found that other backpackers were the most popular source of information (92\%) followed by friends and relatives $(71 \%)$, guide books $(70 \%)$, and the Internet (62\%). Previous studies (Loker, 1992) undertaken before the Internet became a widely available public access resource found that word of mouth and guidebooks were the most commonly used information sources (Cooper et al., 2004). According to Reid et al. (2003), the Internet has added a new dimension to word of mouth by enabling backpackers to share information electronically, including travel recommendations. Recommendations made by backpackers to their fellow travelers might include opportunities to meet other backpackers in a social setting, accommodation, and activities (Murphy, 2001).

Respondents were asked to select which information sources they used from a battery of sources and to rank these on a 1 to 5 scale with 1 indicating the source as being very important. Responses to this question (Table 1) indicate that Japanese backpackers place considerable reliance on guidebooks as a major information source. Guidebooks in this case are published in Japanese and assist users to overcome the language barrier faced by many Japanese backpackers. The Internet was rated as the second most important information source. When gender was cross-tabulated with information sources, the major differences were: travel agents were used by females (58\%) more frequently than males (25\%), and magazines were more likely to be used by females $(36.6 \%)$ than males $(25.5 \%)$.

\section{Motivation for Travel to Australia}

Many factors influence motivations for travel (Adorno, 1991; Urry, 1990) and include level of education, occupation, income, size of the place where tourists normally reside, age, and a range of psychological factors. Family and financial considerations, as well as the tourist image of the destination and the quality of environment visitors expect to find, may influence the choice of a vacation location. For the purposes of this survey it was decided to concentrate on tangible, activity-related motivations, rather than a wider range of factors, primarily because of the resource restrictions faced by the researchers. A later study could include these factors and compare their significance with the tangible factors used in this study. The factors included in this survey were based on discussions held between the researchers, proprietors of backpacker accommodation, and Japanese backpackers, as well as factors

Table 1

Information Sources Considered Valuable by Respondents

\begin{tabular}{lccc}
\hline $\begin{array}{c}\text { Respondents } \\
\text { Information }\end{array}$ & $\begin{array}{c}\text { With Ratings } \\
\text { of Very Valuable } \\
\text { or Valuable }\end{array}$ & $\begin{array}{c}\text { No. of Male } \\
\text { Respondents } \\
(N=60)\end{array}$ & $\begin{array}{c}\text { No. of Female } \\
\text { Respondents } \\
(N=60)\end{array}$ \\
\hline Guidebooks & $73 \%$ & 34 & 31 \\
Internet & $62 \%$ & 36 & 39 \\
Friends/relatives & $54 \%$ & 34 & 31 \\
Brochures & $43 \%$ & 27 & 25 \\
Travel agent & $41 \%$ & 15 & 35 \\
Magazine article & $36 \%$ & 13 & 9 \\
Magazine advertising & $31 \%$ & 15 & 22 \\
Newspaper articles & $18 \%$ & 13 & 9 \\
TV program & $16 \%$ & 10 & 9 \\
Radio & $15 \%$ & 12 & 6 \\
TV advertising & $12 \%$ & 9 & 6 \\
Newspaper advertising & $12 \%$ & 15 & 22 \\
\hline
\end{tabular}


identified in the literature (Reid et al., 2003). To identify the range of motivations that have encouraged Japanese backpackers to visit Australia the respondents were asked to rate a range of motives on a 5point Likert scale. Results are outlined in Table 2.

The results indicate that Japanese backpackers are interested in meeting other tourists as well as local people, and $84 \%$ of respondents considered meeting people as an important factor when they travel. In this case, "people" includes other backpackers as well as local people. In addition, Australia's environment was a major motivation, with the environment, weather, beach, and national parks all ranking as significant motivators. Surprisingly, a much smaller number of respondents considered activities such as surfing, diving, and shopping as an important factor. It is also interesting that $27 \%$ of respondents deem Aboriginal culture as an important factor. Surprisingly, outdoor activities such as surfing, bushwalking, and diving rated relatively poorly and is a point of difference between Japanese backpackers and other segments of backpackers based on nationality.

On a gender basis females indicated their most significant motivation was meeting people $(76 \%)$, closely followed by the environment and a safe destination $(75 \%)$, with good weather $(66 \%)$ in fourth place. Males, on the other hand, indicated that the environment was the most significant factor (65\%) followed by peace and quiet and meeting people $(66 \%)$, with the beach ranked fourth (58\%). Only $30 \%$ of males considered a safe destination as an important factor.

\section{Activities}

Table 3 illustrates the major activates in which respondents were interested in participating. The most significant difference between this study and prior research is the high priority given to learning English. On a gender basis both males and females were primarily interested in learning English $(81 \%$ for both males and females), while the most popular activity for males was meeting locals $(90 \%)$ followed by meeting other tourists $(68.3 \%)$ and visiting historical sites $(68.3 \%)$. The second most popular activity for females was meeting other tourists, followed by visiting pubs and clubs $(62 \%)$. Participating in tours and visiting national parks were also rated as important activities.

Table 2

Factors That Motivate Japanese Backpackers to Visit Australia

\begin{tabular}{lccc}
\hline Variable & $\begin{array}{c}\text { Respondents Who Ranked } \\
\text { These Items as Most } \\
\text { Important or Important }\end{array}$ & $\begin{array}{c}\text { Male Respondents } \\
\text { (Frequency, N=60) }\end{array}$ & $\begin{array}{c}\text { Female Respondents } \\
\text { (Frequency, } N=60)\end{array}$ \\
\hline Meeting people & $70 \%$ & 38 & 46 \\
Environment & $70 \%$ & 39 & 45 \\
Peace \& quiet & $64 \%$ & 38 & 39 \\
Good weather & $62 \%$ & 34 & 40 \\
Beach & $59 \%$ & 35 & 36 \\
Recreation & $57 \%$ & 33 & 35 \\
Friendliness & $56 \%$ & 32 & 35 \\
Tourist attractions & $54 \%$ & 31 & 34 \\
A safe destination & $52 \%$ & 18 & 45 \\
National parks & $51 \%$ & 29 & 32 \\
Value for money & $46 \%$ & 26 & 29 \\
Low price & $40 \%$ & 22 & 26 \\
Australian animals & $39 \%$ & 23 & 24 \\
Travel experience & $38 \%$ & 21 & 25 \\
Unique culture & $38 \%$ & 24 & 22 \\
Food & $34 \%$ & 15 & 26 \\
Surfing & $31 \%$ & 20 & 17 \\
Bushwalking & $29 \%$ & 16 & 19 \\
Diving & $28 \%$ & 18 & 16 \\
Aboriginal culture & $23 \%$ & 15 & 12 \\
\hline
\end{tabular}


Table 3

Activities That Japanese Backpackers Are Interested in Participating

\begin{tabular}{lccc}
\hline Activities & $\begin{array}{c}\text { Respondents Who } \\
\text { Rated Items as Most } \\
\text { Likely or Likely }\end{array}$ & $\begin{array}{c}\text { Male Respondents } \\
\text { (Frequency, N=60) }\end{array}$ & $\begin{array}{c}\text { Female Respondents } \\
\text { (Frequency, }=60 \text { ) }\end{array}$ \\
\hline Learning English & $81 \%$ & 48 & 49 \\
Meeting with locals & $80 \%$ & 41 & 54 \\
Meeting other tourists & $70 \%$ & 41 & 43 \\
Visiting historical sites & $70 \%$ & 40 & 43 \\
Participating in a tour & $58 \%$ & 32 & 37 \\
Visiting a national park & $57 \%$ & 32 & 36 \\
Night clubs, pubs, bars & $56 \%$ & 27 & 39 \\
Museum & $42 \%$ & 24 & 26 \\
Visiting Aboriginal sites & $41 \%$ & 30 & 19 \\
Diving & $40 \%$ & 21 & 27 \\
Surfing & $37 \%$ & 22 & 22 \\
Visiting a restaurant & $34 \%$ & 19 & 22 \\
Bushwalking & $33 \%$ & 18 & 16 \\
Renting a car & $31 \%$ & 21 & 25 \\
Shopping & $29 \%$ & 10 & \\
\hline
\end{tabular}

\section{Places Visited By Japanese Backpackers}

Table 4 illustrates the places that respondents indicated that they had visited or were intending to visit. The sites included in this question were developed as with previous items on the basis of informal discussions held by the researchers with backpacker accommodation providers and Japanese backpackers. Overall, the Great Barrier Reef was the place most likely to be visited (82\%), followed by Ayres Rock (77\%). The third most popular location was Cairns (72\%). There were a number of differences when destination was assessed on a gender basis. In order of preference, males ranked Ayres Rock first (81.6\%), followed by the Barrier Reef (80.0\%) and
Darwin (78.3\%). Female respondents ranked the Great Barrier Reef in first position (93.3\%), followed by Perth $(91.6 \%)$ and Ayres Rock (86.6\%). Cairns' role as a gateway to the Great Barrier Reef may be a major factor in the destination's popularity. Surprisingly, major metropolitan cities did not rank highly and of the major cities visited Perth, on the west coast, was only slightly less popular than Sydney, but more popular than Melbourne. The results indicate that with the time available to them respondents were more likely to visit peripheral areas, particularly those that were noted for their scenic or environmental qualities. On a gender basis the Great Barrier Reef and Perth were more popular with females while Darwin was more popular with males.

Table 4

Places Visited by Japanese Backpackers

\begin{tabular}{lccc}
\hline Places Visited & $\begin{array}{c}\text { Respondents Who } \\
\text { Will Definitely Visit }\end{array}$ & $\begin{array}{c}\text { Male Respondents } \\
\text { (Frequency, } N=60)\end{array}$ & $\begin{array}{c}\text { Female Respondents } \\
\text { (Frequency, } N=60)\end{array}$ \\
\hline Great Barrier Reef & $68 \%$ & 48 & 56 \\
Ayres Rock & $64 \%$ & 49 & 52 \\
Cairns & $60 \%$ & 41 & 46 \\
Sydney & $51 \%$ & 43 & 42 \\
Perth & $50 \%$ & 34 & 55 \\
Gold Coast & $41 \%$ & 37 & 36 \\
Melbourne & $34 \%$ & 35 & 37 \\
Darwin & $34 \%$ & 47 & 23 \\
Brisbane & $33 \%$ & 36 & 30 \\
\hline
\end{tabular}




\section{Discussion and Conclusion}

This study has indicated that Japanese backpackers represent a new form of Japanese travel behavior and do not conform to the stereotype of Japanese group travelers who move in highly organized tour parties from one iconic attraction to another. Nor does this segment conform to the stereotype of high-yield tourists interested in shopping and more interested in the sights than the hosts. On the contrary, the respondents to this survey reveal a group of travelers who are prepared to travel by themselves, beyond the major metropolitan cities to destinations that are known for their environmental attractiveness. The apparent search for the authentic indicates different motivations to those suggested by Cohen (2004), who notes some of the more overt hedonistic characteristics of Western backpackers. In contemporary backpacking a dualism may be emerging where Western and non-Western backpackers share the same physical space and even participate in many of the same activities but exhibit different motivations and occupy different positions in Cohen's (1972) typology of travelers. Compared to the pleasure seeking described by Cohen, Japanese backpackers seem to have more in common with the profile described by MacCannell (1973), as travelers who seek objective authenticity.

This study was designed to provide greater insight into three aspects of Japanese backpackers:

- What information sources do Japanese backpackers use?

- What factors motivate Japanese tourists to travel to Australia as backpackers?

- What activities do Japanese backpackers participate in when they visit Australia?

In relation to the first research issue, considering the information sources Japanese backpackers use, the results indicate that unlike backpackers from other nationalities, who actively seek out fellow travelers for information, Japanese backpackers are more likely to rely on guidebooks and the Internet as their major sources of information (although this may reflect their relative scarcity and perhaps their lack of English). For destinations that have developed a large backpacker market, continued reliance on traditional word of mouth referrals may not be the op- timum strategy to promote an increase in the Japanese sector, and consideration should be given to ensuring that information is available on the web in Japanese.

On the second research issue regarding the motives for Japanese backpacker travel to Australia, the results indicate that respondents placed a high value of learning English and were more interested in meeting people and enjoying the environment than participating in the types of activates that are usually associated with backpackers, such as white water rafting, partying, and soft adventure activities. The finding that learning English was more important than pursuing the range of activities traditionally associated with backpackers appears to reinforce Kajiwara's (1997) observation that the feeling of guilt in seeking pleasure dies hard and education or other "meaningful aspects" of travel continue to play an intrinsic role in the travel patterns of young Japanese. For destinations, and tourism operators within destinations, this is a clear signal that Japanese backpackers require an experience that differs from the experience demanded by other groups of backpackers. Because of the relatively small size of the Japanese sector marketing may be difficult unless operators, including hostels, make a conscious decision to concentrate on this group of backpackers.

The activities identified in this research as being preferred by Japanese backpackers show a number of differences from those activities participated in by other members of the backpacker sector that were previously reported by Tourism Queensland (2003b). It should be noted that while the survey of Japanese backpackers did not attempt to replicate the methodology of the Tourism Queensland (2003a) study, there were a number of findings that can be compared in each report, although with a caveat that it is not statistically valid to make direct comparisons. The Tourism Queensland report found that shopping (89\%) was the most popular activity followed by going to the beach and visiting pubs and clubs. The results of this study paint a different profile for Japanese backpackers, who ranked shopping last out of a possible 15 activities. Similarly, Japanese were interested in meeting locals and demonstrated a higher level of interest in engaging in environmental activities than other groups of backpackers. 
The results reported in this article indicate that the Japanese backpacker market exhibits a number of characteristics that differ from the characteristics of the overall backpacker market, and as a consequence should be treated as a specialized market. This difference may also signal the emergence of a dualism in backpacking as suggested earlier in this article. If a structure of this nature emerges in other non-Western sectors of the backpackers market, destinations will need to consider carefully how they will cope with a differentiated market of this nature. While the study found that Japanese backpackers were interested in learning English there remains a trend towards exclusivity where Japanese backpackers prefer to stay in hostels that have Japanese-speaking staff. If a similar trend were to emerge in other non-Western backpacker segments, destinations will need to consider communication strategies such as teaching second languages to domestic students, hiring foreign guest workers to compensate for the lack of foreign language-proficient domestic workers, and placing a new emphasis on cross-cultural research.

One aspect of this research that may have future implications to the way Japanese travel is viewed is the apparent difference between the backpacker generation and the older generation. In the future, independent travel rather than group travel may emerge as the preferred form of Japanese travel. If this is the case there will need to be a considerable shift made in the way the Japanese market is viewed and the type of experiences that will need to be offered to retain current market shares.

While currently occupying a relatively small place in global backpacker travel, the Japanese market has significant potential for future growth. From the results of the research reported in this article it is apparent that understanding this market will require more than customary market surveying and will need to focus on movements within Japanese culture and how these translate into demand of outbound travel. In a broader context, this research points to the need to recognize that non-Western backpacking may be different from Western backpacking. The assumptions made about backpackers based on observations of Western backpackers may not apply to all backpackers, highlighting the need for an understanding of the impact of national culture dimensions on backpacker travel characteristics.

\section{Biographical Notes}

Dr. Bruce Prideaux is Professor of Marketing and Tourism Management in the School of Business Studies at the Cairns Campus of James Cook University in Australia. He is involved in a number of research programs and heads the Cairns Network of the Sustainable Tourism Cooperative Research Centre. He is currently editing his third book and has authored over 65 referred papers and book chapters.

Hideki Shiga undertook part of this research as a student studying in the Master of Tourism program at the University of Queensland. He subsequently returned to Japan to pursue a career in the tourism industry. Ultimately, his ambition is to own his own chain of backpacker hostels.

\section{References}

Adorno, T. (1991). The culture industry. London: Routledge. Anderson, V., Prentice, R., \& Watanabe, K. (2000). Journeys for experiences: Japanese independent travelers in Scotland. Journal of Travel \& Tourism Marketing, 9(1/2), 129151.

Ateljevic, I., \& Doorne, S. (2004). Theoretical encounters: A review of backpacking literature. In G. Richards \& J. Wilson (Eds.), The global nomad: Backpacker travel in theory and practice (pp. 60-76). Clevedon: Channel View Publications.

Australian Tourist Commission. (2004). Backpacker fact sheet-the backpacker market. Retrieved May 23, 2005, from http://www.tourism.australia.com/content/Research/ Factsheets/Backpacker_July_2004.pdf

Cohen, E. (1972). Toward a sociology of international tourism. Social Research, 39, 164-184.

Cohen, E. (1973). Nomads from affluence: Notes on the phenomenon of drifter-tourists. International Journal of Comparative Sociology, 14(1-2), 89-103.

Cohen, E. (1974). Who is a tourist? A conceptual classification. Sociological Review, 22, 527-555.

Cohen, E. (2004). Backpacking: Diversity and change. In G. Richards \& J. Wilson (Eds.), The global nomad: Backpacker travel in theory and practice (pp. 43-59). Clevedon: Channel View Publications.

Cooper, M. (2002). Flexible labour markets, ethnicity and tourism-related migration in Australia and New Zealand. In C. M. Hall \& A. M. Williams (Eds.), Tourism and migration: New relationships between production and consumption (pp. 73-86). Boston: Kluwer GeoJournal Library Series.

Cooper, M., O’Mahony, K., \& Erfurt, P. J. (2004). Harvest trails: Nomads join the mainstream? In G. Richards \& J. Wilson (Eds.), The global nomad: Backpacker travel in theory and practice (pp. 180-195). Clevedon: Channel View Publications.

Haigh, R. (1995). Backpackers in Australia. Sydney: Bureau of Tourism Research.

Kim, C., \& Lee, S. (2000). Understanding the cultural differences in tourist motivation between Anglo-American 
and Japanese tourists. In K. S. Chon, T. Inagaki, \& T. Ohashi (Eds.), Japanese tourists: Socio-economic, marketing and psychological analysis (pp. 153-170). New York: The Haworth Hospitality Press.

Kininmont, L. (2000). The right mix-facilities for backpackers in Australia. Unpublished Ph.D. thesis, University of Queensland, Ipswich, Queensland, Australia.

Kajiwara, K. (1997). Inward-bound, Outward-bound: Japanese tourism reconsidered. In S. Yamashita, K. Din, \& J. Eades (Eds.), Tourism and cultural development in Asia and Oceania (pp. 164-177). Penerbit UKM: Selangor.

Loker, L. (1992). The Backpacker phenomenon II: More answers to further questions. Townsville, QLD, Australia: Department of Tourism, James Cook University.

MacCannell, D. (1973). Staged authenticity: Arrangements of social space in tourism setting. American Journal of Sociology, 79(3), 589-603.

Murphy, L. (2001). Exploring social interactions of backpackers. Annals of Tourism Research, 28(1), 50-67.

Pearce, P. L. (1990). The backpacker phenomenon: Prelimi- nary answers to basic questions. Townsville: James Cook University of North Queensland.

Reid, S., Slaughter, L., \& Prideaux, B. (2002). Coastal cruising: Targeting the backpacker market in the Whitsunday region, Australia. In Proceedings of Tourism and Hospitality on the Edge CAUTHE 2002 Conference. Fremantle: Promaco.

Richards, G., \& Wilson, J. (2004). Drifting towards the global nomad. In G. Richards \& J. Wilson (Eds.), The global nomad: Backpacker travel in theory and practice (pp. 313). Clevedon: Channel View Publications.

Seddighi, H. R., \& Theocharous, A. L. (2002). A model of tourism destination choice: A theoretical and empirical analysis. Tourism Management, 23(5), 475-487.

Tourism Queensland. (2003a). International backpackers market. Retrieved April 19, 2004, from http:// www.destinationqueensland.com/tq.cfm

Tourism Queensland. (2003b). International research summary Japan. Retrieved August 30, 2003, from http:// www.qttc.com.au/home.htm

Urry, J. (1990). The tourist gaze. London, UK: Sage. 